\title{
LOS PRESUPUESTOS DE LA RESPONSABILIDAD POR NUESTRAS EMOCIONES *
}

\author{
Daniel González Lagier \\ Universidad de Alicante
}

RESUMEN. En este trabajo se analizan tres presupuestos de la adscripción de responsabilidad por nuestras emociones. De acuerdo con el primer presupuesto, para poder adscribir responsabilidad por nuestras emociones, éstas deben poder ser evaluadas como racionales o irracionales: el segundo presupuesto consiste en que debemos tener algún grado de control sobre nuestras emociones para que éstas se nos puedan reprochar; el tercer presupuesto es su capacidad de motivar acciones. En el trabajo se sostiene que las emociones satisfacen estos tres requisitos y se trata de mostrar, además, que el Derecho penal de nuestros sistemas jurídicos tiene en cuenta, a la hora de modular la responsabilidad por nuestras acciones, si éstas fueron motivadas por emociones adecuadas o inadecuadas (es decir, tiene en cuenta cierta responsabilidad por nuestras emociones).

Palabras clave: emoción, acción, responsabilidad, Derecho penal.

ABSTRACT. This paper discusses three prerequisites for ascription of responsibility for our emotions. According to the first prerequisite, assignment of responsibility for our emotions requires them being subject to evaluation as rational or irrational; the second prerequisite is that some degree of control over our emotions is a necessary condition of reproach; the third assumption is their ability to motivate action. The paper argues that emotions meet indeed these three requirements and attempts to show that the Criminal Law of our legal systems does consider as a factor that modulates ones own responsibility for his/her actions their being motivated by the appropriate or inappropriate emotions (i. e. it makes us to some extent responsible for our emotions).

Keywords: emotion, action, responsibility, Criminal Law.

\footnotetext{
* Fecha de recepción: 29 de junio de 2009. Fecha de aceptación: 30 de julio de 2009.
} 


\section{INTRODUCCIÓN: LAS CONDICIONES DE LA RESPONSABILIDAD EMOCIONAL}

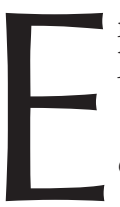

n este trabajo quiero plantear dos cuestiones que pueden ayudar a esclarecer las relaciones entre las emociones y la responsabilidad:

I. ¿Tiene sentido atribuir responsabilidad por tener una u otra emoción? ¿Se nos puede reprochar o aplaudir por tener una u otra emoción?

II. ¿Cómo influyen las emociones en las atribuciones de responsabilidad por las acciones que hemos realizado bajo el influjo de una emoción?

I y II son preguntas distintas, pero relacionadas. Quiero sugerir que la respuesta a I es afirmativa, es decir, que se nos puede censurar (o alabar), sin violentar los presupuestos normalmente aceptados de la adscripción de responsabilidad, por tener una u otra emoción. Respecto de II sostendré que cuando el Derecho atribuye responsabilidad penal por las acciones realizadas en contextos emocionales (en los supuestos, por ejemplo, en los que se aplica la atenuante de arrebato u obcecación o cierto tipo de agravantes, como la de actuar por móviles racistas) presupone un juicio acerca de la corrección o no de determinadas emociones (es decir, presupone una respuesta afirmativa a I). Al mismo tiempo, quiero sugerir que para dar cuenta del papel que el Derecho concede a las emociones en la atribución de responsabilidad por nuestras acciones hay que superar la imagen tradicional de las emociones como fuerzas ciegas, incontrolables y ajenas a la esfera de la razón.

Comencemos con I. Censurar las emociones de otros es algo que, de hecho, hacemos con cierta frecuencia. Dirigimos nuestros reproches a quien se enfada con excesiva asiduidad, a quien manifiesta sentimientos racistas, a quien carece de compasión, a quien es en exceso envidioso... La cuestión es si tales atribuciones de responsabilidad están justificadas. Para que lo estén, sería necesario que las emociones tuvieran ciertos rasgos que no es obvio que tengan, al menos de acuerdo con una imagen de las mismas que está muy extendida. La responsabilidad presupone la libertad, y la libertad presupone la racionalidad. Si la vieja contraposición entre pasión y razón, entre las emociones y la racionalidad, es cierta, entonces las emociones escapan a los juicios de responsabilidad. En primer lugar porque atribuir responsabilidad por una emoción presupone que esa emoción es inadecuada en algún sentido relevante, pero si las emociones no son racionales (en el sentido de que caen fuera del ámbito de fenómenos que podemos calificar como racionales o irracionales) no pueden ser evaluadas como justificadas o no (al menos, en el sentido de «evaluadas» que es pertinente para el reproche). En segundo lugar porque si no son —al menos, en alguna medida— libres, esto es, controlables en algún grado por nuestra voluntad, entonces tampoco está justificado su reproche.

A la primera de estas condiciones, a la posibilidad de evaluar las emociones como justificadas o no desde ciertos puntos de vista que involucran la razón, la llamaré condición de evaluación; a la segunda condición, el ser controlables en alguna medida, la llamaré condición de control. A estos requisitos para que pueda atribuirse responsabilidad por una emoción habría que añadir un tercero. Si las emociones no tuvieran ningún papel en nuestra conducta no parece que se pudiera reprochar una emoción desde un 
punto de vista moral o jurídico. El hecho de que ciertas emociones tienden a promover conductas inadecuadas (y el hecho de que otras emociones tienden a promover conductas adecuadas o a evitar conductas inadecuadas) es también relevante para la adscripción de responsabilidad por las emociones mismas. Es más, como veremos, una emoción puede considerarse inadecuada precisamente porque promueve conductas inadecuadas. Aquí aparece una nueva condición de la responsabilidad emocional: que las emociones tengan fuerza motivacional. La llamaré la condición de motivación.

¿Reúnen las emociones estas tres condiciones? Para contestarlo necesitamos embarcarnos en algunas disputas conceptuales acerca de la noción de emoción.

\section{LAS EMOCIONES COMO ESTADOS MENTALES}

Las emociones son un tipo de fenómeno que solemos calificar de mental (al igual que hacemos con creencias, deseos, intenciones, decisiones, rasgos de carácter, etc.). En la filosofía de la mente es usual distinguir dos tipos de fenómenos mentales: Los estados intencionales y los estados fenomenológicos ${ }^{1}$. Los estados intencionales (que no hay que confundir con el estado mental que consiste en tener una intención, que es sólo un estado intencional más) se caracterizan por «tener un contenido ante el cual un sujeto adopta cierta actitud: creencias, deseos, intenciones, esperanzas, etc.» ${ }^{2}$. De esta manera, la intencionalidad de la mente —en palabras de J. SEARLE— «es aquella propiedad de muchos estados y eventos mentales en virtud de la cual éstos se dirigen a, o son sobre o de, objetos y estados de cosas del mundo. Si, por ejemplo, tengo una creencia, debe ser una creencia de que tal y tal es el caso; si tengo un temor debe ser de algo o de que algo ocurrirá; si tengo un deseo, debe ser un deseo de hacer algo, o de que algo suceda o sea el caso» ${ }^{3}$. Los estados fenomenológicos, por el contrario, «se caracterizan por una cualidad sentida, o un modo de aparecer al sujeto: sensaciones de dolor o placer, post-imágenes, experiencias auditivas, olfativas, visuales, etc.» ${ }^{4}$. Los estados intencionales puros, como las creencias, no tienen un componente fenomenológico (no se «sienten»; sabemos que tenemos una creencia, pero no hay una sensación vinculada a ella). Los estados fenomenológicos puros, por su parte, se sienten, pero no poseen contenido, no se refieren a nada (no podemos decir de un dolor de muelas que es un dolor sobre o acerca de algo). ¿Qué lugar ocupan las emociones? ¿Son estados intencionales, fenomenológicos o quizá mixtos?

La que puede considerarse la concepción tradicional de las emociones (que se corresponde con la imagen popular de las mismas) las ha considerado como estados fenomenológicos. Esta concepción ha sido defendida por autores como DESCARTES ${ }^{5}$ y W. JAMES. Para estos autores, las emociones son las percepciones de los cambios fisiológicos que ocurren en nuestro cuerpo en determinadas circunstancias. Así, JAMES afirma:

\footnotetext{
1 A partir de estos dos tipos de estados podemos derivar otros subtipos, como los estados mixtos o las disposiciones.

2 MoYA, 2006, p. 18.

3 SEARLE, 1992, p. 17.

4 MoYa, 2006, p. 18.

5 Para una interpretación distinta de la concepción cartesiana de las emociones, vid. CASACUBERTA, 2000, pp. 33 y ss.
} 
«[mi tesis es que] los cambios corporales siguen directamente a la percepción del hecho existente, y que nuestro sentimiento de esos cambios a medida que ocurren es nuestra emoción» ${ }^{6}$. De manera que, para esta concepción, una emoción como el miedo consistiría en la sensación de que mi corazón se acelera, mi respiración se agita, mis manos sudan, mi vello se eriza, etc. HumE, por su parte, también identificó a las emociones con sensaciones («impresiones», las llamaba), que podían ser agradables o desagradables.

Este tipo de concepciones sustentan la atribución a las emociones de una serie de rasgos (algunos de los cuales R. SOLOMON considera «mitos» sobre las emociones), que completan la imagen más extendida o estándar de las mismas:

a) Son fuerzas que experimentamos, «pasiones», en el sentido de que respecto de ellas somos sujetos pasivos; no son cosas que hacemos, sino cosas que nos ocurren.

b) Siguen sus «propias leyes», son básicamente incontrolables. Forman parte de una naturaleza innata en el hombre, no son fenómenos culturales.

c) Escapan del ámbito de la razón. Más bien entorpecen el razonamiento correcto.

d) Las emociones son fuerzas que empujan a las personas a actuar sin intervención de la voluntad o de la razón, sin que medien pensamientos o juicios acerca del entorno. Son «fuerzas ciegas».

e) Proporcionan, por tanto, a lo sumo, explicaciones causal-mecanicistas de la conducta, pero no explicaciones basadas en razones.

f) Las emociones mismas deben ser explicadas en términos estrictamente causales.

g) Aunque pueden ir asociadas a creencias, éstas son más bien fenómenos concomitantes, que no forman parte de la estructura de la emoción.

ARISTÓTELES, por el contrario, había caracterizado a las emociones de manera que parece clasificarlas, no como un estado fenomenológico, sino como un estado mixto. En la Retórica, hizo tres importantes observaciones sobre las emociones:

a) En primer lugar, las emociones están vinculadas a nuestros juicios o creencias, en el sentido de que las emociones pueden modificar o cambiar nuestra manera de pensar sobre algo, o nuestra manera de juzgarlo. Son «aquello por lo que los hombres cambian y difieren para juzgar».

b) En segundo lugar, las emociones son causadas, a su vez, por otras creencias. Así se desprende de su análisis de algunos tipos de emociones: la ira, que es causada por la creencia de que hemos sido tratados injustamente; el miedo, que es causado por la creencia de que nos amenaza un mal inminente, etc.

c) En tercer lugar, las emociones están asociadas a sensaciones, que pueden ser de «pena» $\mathrm{o}$ «placer». Las emociones «se sienten» de una manera peculiar y algunas de esas sensaciones resultan placenteras y otras dolorosas.

Una concepción de las emociones como ésta, que las vincula estrechamente a las creencias (sin olvidar su aspecto fenomenológico), parece superar algunas deficiencias de las concepciones fenomenológicas ${ }^{7}$. El principal problema de estas últimas es que

${ }^{6}$ JAMES, 1992, p. 143.

7 No han faltado autores que, en su pretensión de destacar el aspecto intencional o cognoscitivo de las emociones, esto es, su vinculación a creencias, han tendido a dejar en un segundo plano sus aspectos fenomenológicos. En realidad, en gran medida la distinción entre teorías que clasifican de una u otra manera a las emociones es una cuestión de acentos. 
no dan cuenta de ciertos rasgos relevantes que solemos atribuir a las emociones. Por ejemplo, los siguientes:

a) Las emociones parecen asociarse a creencias y deseos, y surgir en combinación con ellos. Como señalaba ARISTÓteles, es la creencia de que me amenaza un mal lo que genera mi miedo. Mi miedo tiene así una causa identificable: la evaluación que hago de la situación, y lejos de ser una fuerza ciega, me conmina actuar de manera que me aleje de ese peligro.

b) En segundo lugar, muchas emociones tienen un contenido o se refieren a un objeto, esto es, poseen intencionalidad, en el sentido filosófico. Mi miedo es miedo de algo, mi cólera es cólera por algo, mi amor es amor hacia alguien, etc.

c) En tercer lugar, tiene sentido decir que una emoción es apropiada o no, que está justificada o no, cosa que sería imposible si las emociones fueran sensaciones o conductas causalmente condicionadas y completamente involuntarias.

d) En cuarto lugar, las emociones pueden actuar como motivos para la acción y sirven para ofrecer explicaciones teleológicas de la conducta, esto es, explicaciones basadas en combinaciones de deseos y creencias acerca de cómo satisfacerlos (explicaciones que remiten a razones, por tanto).

e) En quinto lugar, las emociones son susceptibles de cierto control y son sensibles al entorno cultural: hay emociones universales (son las llamadas emociones primarias, que tienen una utilidad evidente para la supervivencia humana: como el miedo, la ira o la repugnancia), pero hay otras que sólo se dan en ciertas culturas o que experimentan fuertes variaciones de una cultura a otra (como la culpa o la envidia).

Hoy día, puede decirse que la mayoría de los filósofos, y muchos psicólogos, aceptan que las emociones tienen un componente intencional o de contenido. Así, por ejemplo, M. Nussbaum sostiene que «las creencias están estrechamente conectadas con las emociones: parecen ser parte de lo que es la emoción misma» ${ }^{8}$, y para W. LYONS los elementos necesarios para que pueda hablarse de emoción son un juicio evaluativo acerca de algo y una alteración fisiológica, siendo el primero el elemento necesario para identificar la emoción ${ }^{9}$. Otros autores cognitivistas son filósofos como SpinOza, Brentano, A. KenNy, Thalberg, etc., y psicólogos como LÁZARUs, Fridja, etc. No obstante, al destacar la dimensión intencional de las emociones no hay que minusvalorar su dimensión fenomenológica. Una concepción excesivamente centrada en la creencia y los deseos que aparecen vinculados a las emociones y que no dé cuenta de la importancia del hecho de que es característico de las emociones sentirse como algo agradable o desagradable, que suelen ir acompañadas de cambios fisiológicos y de una expresión corporal típica, sería una concepción reductivista y excesivamente racionalista de las mismas.

\section{LA ESTRUCTURA DE LAS EMOCIONES}

Una vez asumido que las emociones son estados a la vez fenomenológicos e intencionales, se puede tratar de precisar algo más su estructura, por medio del análisis de

\footnotetext{
8 Nussbaum, 2006, p. 41.

9 LYONS, 1993, p. 79.
} 
lo que podríamos llamar los elementos de las emociones. Estos elementos están presentes en las situaciones emocionales típicas y se ordenan en una «historia» o «proceso» característico: Pensemos, por ejemplo, en el miedo: supongamos que observo un gran perro que me mira amenazador con ojos inyectados en sangre y fauces que dejan entrever enormes colmillos. Lo evalúo como un evento peligroso en relación con un valor importante para mí: mi vida o mi integridad física. La emoción se enfocará hacia el perro, que es el objeto de mi miedo. Se producirá una aceleración de mis latidos, comenzaré a sudar, se erizarán los pelos de mis brazos, aumentará el nivel de adrenalina en mi cuerpo; sentiré algunas de estas reacciones de mi cuerpo, junto con un nudo en el estómago y una sensación en general desagradable. Al mismo tiempo, mis cejas se elevarán y contraerán, mis párpados superior e inferior se elevarán, los labios dibujarán una mueca causada por la tensión, mi cuerpo se encogerá y correré hacia la puerta más cercana. Finalmente, al entrar en la casa me siento seguro y la emoción finaliza.

En casos como el descrito podemos distinguir los siguientes elementos:

1. Una creencia o evaluación.

2. Un objeto intencional.

3. Un conjunto de cambios fisiológicos.

4. La sensación.

5. La expresión de la emoción.

6. Una tendencia a la acción.

Un análisis completo de la emoción requeriría profundizar en todos estos elementos. No obstante, el resultado de este análisis no sería exactamente una definición, porque no se trata de condiciones necesarias y suficientes del concepto sino, más bien, de rasgos presentes en los casos centrales o típicos de emociones, pero no en otros casos marginales. Convendría tratar al concepto de emoción más como un conjunto de fenómenos que guardan entre sí cierto parecido de familia que como una noción precisa y bien definida. De estos elementos, los que más nos interesan para el tema que tratamos de desarrollar son la creencia y la sensación.

a) La creencia o juicio evaluativo: A menudo se piensa que las emociones son suscitadas por ciertos hechos o circunstancias externas; ciertamente, esto es lo que parece asumir la psicología popular y también el Derecho, que requiere para que haya una emoción susceptible de producir arrebato u obcecación la existencia de un estímulo externo poderoso ${ }^{10}$. Sin embargo, como han señalado Aristóteles y los autores racionalistas, las emociones son suscitadas no por los hechos externos sino por creencias sobre hechos externos, reales o no, o incluso sobre otros hechos psicológicos. ELSTER, por ejemplo, señala que las emociones pueden ser generadas —además de por las típicas creencias acerca de hechos externos inmediatos- por creencias acerca de las emociones propias (por ejemplo, la percepción de que se siente miedo puede provocar vergüenza), creencias acerca de las emociones de otras personas (la creencia de que otra persona me odia puede generar miedo en mí), creencias acerca de las motivaciones de otras personas (mi enfado puede deberse a creer que Alfredo pisa mi césped sólo para fastidiarme), creencias acerca de las creencias de otras personas (me entristece lo que creo que los demás piensan de mí), creencias sobre hechos imaginarios (como en algunos casos de celos),

\footnotetext{
10 Vid., por ejemplo, la STS 59/2002, de 25 de enero.
} 
creencias de las que no estamos seguros o a las que asignamos sólo cierto grado de probabilidad, que incluso podría ser bajo (como en ciertos miedos irracionales), creencias contrafactuales (acerca de lo que hubiera podido suceder), creencias «como si» (como sucede con las emociones provocadas por las novelas o las películas) ${ }^{11}$, etc.

Sin embargo, no todas las creencias pueden suscitar emociones. Como señala M. Nussbaum, debe tratarse de una creencia evaluativa, esto es, de un juicio de valor acerca de cómo determinado hecho puede afectar a un objetivo importante o el bienestar mío o de mis allegados. Las emociones, en definitiva, incluyen una evaluación de las propiedades de un objeto o de un fenómeno como factores que inciden en la satisfacción o frustración de un deseo. Cuando el objeto o fenómeno se evalúa como algo que contribuye a la satisfacción del deseo lo llamaremos facilitador. La emoción en ese caso es positiva. Por el contrario, cuando se evalúa el objeto o fenómeno como un obstáculo lo llamaremos obstaculizador y en este caso la emoción es negativa (también puede haber emociones neutrales, como, en ciertos casos de sorpresa). Por ejemplo, es el considerar que un animal es peligroso para mi integridad lo que despierta mi miedo; mi ira aparece porque juzgo que alguien me ha tratado de manera injusta, dañándome; mi vergüenza, porque creo que algo deforma la imagen que quiero dar de mí; la alegría porque me parece que estoy a punto de alcanzar la meta por la que tanto me he esforzado; etc.

Tampoco hay que pensar que las creencias que activan las emociones han de ser creencias completamente formadas y completamente conscientes. Basta una «porción significativa de la evidencia perceptual disponible» ${ }^{12}$ para desatar la emoción. Incluso se ha sugerido que la creencia, en ocasiones, es posterior a los cambios fisiológicos o a la sensación: al parecer, hay dos circuitos cerebrales que conectan los estímulos externos y las reacciones de temor; uno de ellos no permite procesar creencias o evaluaciones, aunque es más rápido (es, por tanto, una ventaja evolutiva). En este caso, primero nos asustamos (sentimos el miedo) y después (quizá habiendo ya reaccionado) sabemos por qué (es decir, el aspecto cognitivo, en estos supuestos, antecedería al aspecto fenomenológico).

b) La sensación: A diferencia de los estados intencionales puros, y a semejanza del dolor, el hambre, las náuseas o el vértigo, las emociones suelen ir acompañadas de una sensación. Introspectivamente, la sensación «nos avisa» de que estamos bajo una emoción, aunque es discutible si podemos identificar esa emoción sólo a partir de la sensación que la acompaña. La sensación que acompaña a la emoción tiene dos dimensiones: por un lado, es la sensación o percepción de algunos de los cambios fisiológicos que ocurren en nuestro cuerpo cuando experimentamos miedo, amor, ira, odio, tristeza, etc. Pero también tiene en muchas ocasiones un componente hedónico, esto es, la percepción de dichos cambios fisiológicos puede ser considerada como placentera o dolorosa o, más genéricamente, agradable o desagradable. Esto hace que, en ocasiones, se hable de emociones positivas y emociones negativas. Parece haber una correspondencia entre evaluar un hecho como favorable en relación con un objetivo o deseo y la sensación agradable, por un lado, y la evaluación de un hecho como un obstáculo para la satisfacción del deseo y la sensación desagradable, por otro.

\footnotetext{
11 ELSTER, 2002, p. 309.

12 La expresión es de Greenspan. Vid. RodríGuez GonZÁlez, 1999, p. 144.
} 
Este componente fenomenológico puede entrar a formar parte en los complejos motivacionales de la conducta. Así, la vergüenza y la culpa fueron tan insufribles para Edipo que se arrancó los ojos. Más adelante volveremos sobre este punto.

\section{EMOCIONES Y RACIONALIDAD: LA CONDICIÓN DE EVALUACIÓN}

Antes hemos dicho que la responsabilidad presupone la libertad y que la libertad presupone la racionalidad. Ahora podríamos añadir que la racionalidad presupone la intencionalidad: si un estado mental carece de contenido representacional, si no se refiere a nada o no tiene significado, cae fuera del ámbito de la razón. Un dolor o una punzada, las meras sensaciones, no son racionales o irracionales. Por ello, explicar en qué sentidos se puede decir que una emoción es racional o está justificada requiere abandonar la concepción de las emociones como estados fenomenológicos puros. Sólo desde una teoría que dé cuenta de que las creencias son un ingrediente de las emociones se puede dar cuenta de lo que he llamado la condición de evaluación.

¿Qué criterios usamos para evaluar las emociones? Veamos, sin pretensión de exhaustividad, algunos de ellos.

En primer lugar, podemos decir que una emoción está justificada — desde el punto de vista de la racionalidad cognoscitiva- si se basa en creencias a su vez justificadas. Por el contrario, un defecto en la justificación de la creencia que suscita la emoción hará que la emoción correspondiente sea irracional o no esté epistémicamente justificada. Así, nos podemos encontrar con emociones irracionales por basarse en creencias dogmáticas o sin evidencia a su favor (por ejemplo, la tristeza causada por la creencia de que un ser querido padece una grave enfermedad es irracional si no tenemos ningún dato, o los que tenemos son insuficientes, para pensar que realmente es así); o emociones irracionales por basarse en una creencia derivada a partir de creencias a su vez injustificadas (por ejemplo, el miedo causado por la creencia de que me sobrevendrá un mal, si esta creencia se deriva a su vez de alguna convicción supersticiosa (como que «me han echado mal de ojo»), o emociones irracionales por basarse en una inferencia inadecuada (durante la Segunda Guerra Mundial los habitantes de ciertos barrios de Londres estaban especialmente atemorizados por las bombas alemanas, puesto que inferían del hecho de que las bombas tendieran a caer agrupadas que los alemanes tenían la intención de realizar bombardeos selectivos sobre tales barrios, ignorando que los procesos aleatorios tienden a generar grupos ${ }^{13}$ ).

Un segundo tipo de irracionalidad de la emoción, también vinculado con las creencias que las generan, es el que se da por falta de correspondencia entre el tipo de creencia y el tipo de emoción. Es el tipo de racionalidad que cuestionamos cuando la emoción no parece corresponderse con el tipo de creencia. Por ejemplo, cuando sentimos ira (en lugar de compasión) hacia aquellos a quienes hemos hecho daño, u odio (en lugar de agradecimiento) a quienes nos han ayudado.

Una variante del anterior tipo de irracionalidad emocional es el de las emociones excesivas o, por el contrario, el de las emociones insuficientes. En este caso ya no es

13 Elster, 2002, p. 380. 
que haya alguna incongruencia entre el tipo de creencia y el tipo de emoción, sino que hay una desproporción entre los juicios de valor y las creencias subyacentes a la emoción y la intensidad de la misma. Un perro puede causar temor, pero un excesivo temor causado por un perro pequeño y amistoso es irracional. La ira causada por una broma torpe, o la preocupación obsesiva por un pequeño incidente (como haber dicho un pequeño inconveniente que nadie parece haber advertido), son ejemplos de este tipo de irracionalidad, pero también la frialdad ante el fallecimiento de un ser querido, la indiferencia ante la pobreza en el mundo o la temeridad ante un elevado riesgo.

¿Qué es lo que hace que en estos casos califiquemos de irracional la emoción? El tipo de juicio de inadecuación que está en juego tanto en este caso como en el anterior es, en cierto sentido, normativo, esto es, se trata de emociones irracionales por contravenir estándares de normalidad de carácter social o cultural. Estos estándares diseñan el modelo de «hombre razonable» y la racionalidad o irracionalidad de la emoción se mide en función de cuál hubiera sido la emoción de un hombre razonable (y qué intensidad hubiera tenido) en las circunstancias de las que se trate. Como señala M. NussBaum, la evaluación de las emociones desde el punto de vista del «hombre razonable» juega un papel muy relevante en el valor que en el Derecho se le concede a las emociones a la hora de determinar la responsabilidad penal ${ }^{14}$.

En ocasiones, una emoción nos parece irracional porque no vemos que tenga ningún sentido a la luz de los objetivos cercanos o remotos del sujeto. Un amor no correspondido o imposible sostenido más allá de lo razonable, el odio que convierte a la venganza en el único objetivo relevante para el sujeto, los celos (incluso fundados) que acaban con la relación que pretenden proteger, etc., son emociones que nos pueden parecer irracionales porque tienen consecuencias destructivas, invasivas, desplazan objetivos relevantes de cualquier plan de vida razonable y llevan al sujeto a realizar acciones insensatas (también aquí el juicio de irracionalidad puede descansar en normas y convenciones sociales acerca de «lo razonable»). Por el contrario, otras veces las emociones parecen adecuarse a una estrategia conveniente para el sujeto. El juicio acerca de la adecuación estratégica de las emociones puede centrarse en objetivos inmediatos del sujeto o en objetivos a largo plazo, e, incluso, puede hacerse en relación con su bienestar futuro, la «buena vida», y hasta en relación con «la vida buena» (aunque en estos últimos casos, cuando se juzga la racionalidad a largo plazo, lo racional o irracional no es tanto un episodio emocional como tener una cierta disposición emocional).

\section{EMOCIONES Y VOLUNTAD: LA CONDICIÓN DE CONTROL}

La segunda condición de la posibilidad de atribuir responsabilidad por las emociones que señalábamos al principio era la posibilidad de su control. Por «control de la emoción» me refiero no al control de su expresión (que es posible, hasta cierto punto) y de las acciones que genera, sino a la posibilidad de evitar o provocar una emoción. Si las emociones son fuerzas que no dependen de nuestra voluntad (como afirma la concepción tradicional), entonces no se nos puede hacer responsables de haber tenido una emoción injustificada (o de no haber tenido una emoción justificada).

\footnotetext{
${ }^{14}$ Nussbaum, 2006, pp. 52 y ss.
} 
Muchas expresiones, como «me sentí inundado de tristeza», «me asaltó el temor de que...», «enloquecí de furia», etc., parecen indicar que las emociones nos asaltan, que no las elegimos. Sin embargo, algunos autores han insistido en lo contrario (por ejemplo, SARTRE). Actualmente, el más vehemente es probablemente R. C. SOLOMON, quien acepta que las emociones, en ocasiones, escapan a nuestro control, pero considera que se trata de casos sumamente excepcionales, y afirma que: «La mayoría de nuestras emociones, la mayor parte del tiempo, no escapan por completo a nuestro control. No sólo nos suceden, sino que somos responsables de ellas. Las practicamos y, en muchos casos, las elegimos, aunque sea inconscientemente» ${ }^{15}$.

Mi opinión es que la concepción tradicional está equivocada si se entiende como una generalización extensible a todas las emociones, pero la manera de presentar la tesis contraria por parte de SOLOMON es un poco exagerada. No parece apropiado afirmar que las emociones se eligen (y menos aceptar algo así como una elección inconsciente), porque no podemos tener una determinada emoción sólo con decidirlo. No obstante, eso no quiere decir que escapen totalmente de nuestro control. En cierta medida, las emociones son «manipulables». El propio SOLOMON, cuando ofrece ejemplos para explicar en qué sentido «elegimos» nuestras emociones, nos pone sobre la pista de ello. Veamos uno de tales ejemplos:

«Llevo años sosteniendo que "enamorarse" es una cuestión de elección, de múltiples decisiones. El amor puede comenzar con un encuentro, que puede ser maravilloso, mágico y todo lo demás. Los ojos se quedan clavados y las miradas se atraviesan. La más trivial de las conversaciones despierta enseguida un interés mutuo, trayectorias mutuamente excitantes, compatibilidad mutua. Pero entonces tiene lugar una serie de elecciones y decisiones, tanto mutuas como individuales. ¿Debo quedarme o marcharme? ¿Debería volver a verle? ¿Con mis amigos o sin ellos? ¿Deberíamos quedar para comer o para cenar? ¿En un sitio romántico o no? ¿Debería darle un beso de buenas noches? ¿Debería presentarle a mis padres? Y cada una de estas decisiones supone también la decisión de fomentar o entorpecer la relación creciente y los sentimientos que van surgiendo. Y luego están las modalidades más directas y habitualmente silenciosas de preparación emocional. Uno piensa: "iQué comentario tan encantador!", "iQué mirada tan inteligente!", "Me pregunto cómo serían unas vacaciones románticas juntos", "Me pregunto qué clase de amante será!". Y luego los pensamientos imaginativos, esperanzados, fantasiosos: repasar retrospectivamente la conversación incluyendo un embarazoso análisis crítico de cada palabra y cada matiz, ensayando posibles continuaciones. Y luego recrearse reiteradamente en las imágenes: caminando juntos por la playa, haciendo el amor juntos, teniendo niños juntos. El amor es un proceso de escalada deliberada» ${ }^{16}$.

Con este ejemplo debería quedar claro que el control que ejercemos sobre las emociones es indirecto e inseguro. Es muy posible que hagamos todo lo que dice Solomon $\mathrm{y}$, sin embargo, no lleguemos a enamorarnos. Todo el proceso se puede convertir en un intento fracasado y un tanto ridículo y artificial de enamorarse.

Para dar cuenta del grado de control que ejercemos sobre nuestras emociones puede ser útil distinguir entre: $a$ ) estados de cosas dentro del control del agente; $b$ ) estados de cosas fuera del control del agente, y $c$ ) estados de cosas parcialmente dentro del control del agente ${ }^{17}$. Un estado de cosas está dentro del control de un agente cuando

\footnotetext{
15 Solomon, 2007, p. 261.

16 Solomon, 2007, p. 266.

17 GonZÁlez LagIER, 1997, p. 172.
} 
éste puede realizar una acción que, en condiciones normales, es condición suficiente para producir ese estado de cosas (cerrar una puerta); un estado de cosas está fuera del control del agente cuando el agente no puede realizar una acción que sea condición suficiente, o necesaria, o preparatoria ${ }^{18}$ para producir el estado de cosas (hacer que llueva); y un estado de cosas está parcialmente dentro del control del agente cuando éste sólo puede realizar condiciones necesarias, pero no suficientes, o condiciones preparatorias para producir ese estado de cosas (adelgazar diez kilos).

Trasladar esto al caso de las emociones nos permitiría afirmar que un estado emocional es un estado de cosas parcialmente dentro del control del agente: algo que podemos procurar hacer (o evitar), pero sin garantía de éxito. Enfadarse, asustarse, arrepentirse, etc., no son acciones, pero pueden ser consecuencia de nuestras acciones, esto es, podemos hacer cosas que son condiciones necesarias para tener o evitar una emoción, o que contribuirán a que ésta aparezca o desaparezca. Nuestro control de las emociones es, por tanto, indirecto y menos fiable que el de nuestras acciones.

¿Qué tipo de cosas podemos hacer para ejercer este control indirecto sobre nuestras emociones?

a) En primer lugar, podemos tratar de corregir nuestras creencias y juicios evaluativos, realizar lo que algunos psicólogos han llamado una «reevaluación». Hemos visto que las emociones surgen cuando evaluamos un evento (real o imaginario) como facilitador u obstaculizador de un deseo. De manera que, quizá, si podemos cambiar nuestras creencias, podemos evitar o suprimir o provocar una emoción, como sugería Aristóteles en la Retórica. Por esta vía podríamos tratar de controlar las emociones irracionales por basarse en creencias no justificadas. Por tanto, para tener las emociones apropiadas deberíamos empezar por asegurarnos de que nuestras creencias están justificadas.

Ahora bien, ¿podemos controlar nuestras creencias? Muchos autores rechazan esta idea. Niegan que tener una creencia sea una cuestión de mera decisión. También las creencias serían, en este sentido, pasivas. No obstante, por otro lado parece plausible pensar que algunas creencias pueden ser aceptadas o rechazadas, que podemos tratar de ampliar nuestro conocimiento para modificar ciertas creencias o confirmarlas, que podemos examinarlas críticamente y someterlas a juicio. En palabras de MOSTERÍN: «Cuando estoy completamente seguro de algo, cuando no puedo ponerlo en duda, digo que ese algo es evidente para mí (...) Las creencias obligatorias, las creencias que no podemos dejar de creer, son relativamente poco frecuentes. En la mayor parte de los casos no sentimos una confianza tan abrumadora, inmediata y total en la verdad de una idea que no tengamos más remedio que creerla (...) En esos casos, nuestra creencia no está acompañada de ningún sentimiento de certeza que nos obligue a creerla. No se trata de una creencia obligatoria, sino de una creencia voluntaria» ${ }^{19}$.

Para MOSTERÍN la noción de «aceptación» de una creencia permite distinguir entre las creencias «voluntarias» (que son precisamente las que surgen como resultado de esa aceptación) y las creencias «obligatorias». Sin embargo, me parece que ni siquiera

18 Por condición preparatoria o contribuyente entiendo aquella que por sí sola no es ni suficiente ni necesaria, pero contribuye a que se produzca el resultado.

19 Mosterín, 1987, p. 133. 
sobre las creencias voluntarias tenemos un control completo - y, en este sentido, no es del todo apropiado llamarlas voluntarias-, porque aunque la fase final (la aceptación) sea una cuestión de decisión, las fases previas, igualmente necesarias para que tenga la creencia, pueden estar fuera de mi control: esto es lo que quiere decir que no puedo decidir, sin más, tener una creencia y tenerla como resultado de mi decisión. Hace falta, por ejemplo, que primero haya pasado por el estado de creencia dubitativa; hace falta que se hayan dado las circunstancias para que la creencia llegue a mi consideración, se me «presente» para su aceptación. Por otro lado, tampoco las creencias obligatorias o involuntarias están totalmente fuera de mi control: puede que las evidencias se me presenten sin que yo haga nada, pero también puedo ir a buscarlas: puedo ponerme a reflexionar, puedo buscar razones, preguntar opiniones, etc., o evitar hacerlo. En definitiva, creo que podríamos decir que las creencias, como las emociones, son estados sólo parcialmente dentro del control del agente. En este sentido, somos, en cierta medida, responsables de nuestras creencias.

Obviamente, no se nos puede pedir que sometamos la ingente cantidad de creencias con las que todos «cargamos» a un proceso de revisión crítica para asegurarnos de que todas ellas están justificadas; sin embargo, las emociones, contrastadas socialmente, podrían servir precisamente para detectar qué creencias deberíamos revisar. Supongamos que me doy cuenta de que suelo tener con frecuencia una determinada emoción (por ejemplo, me enojo con facilidad cuando alguien me gasta una broma) y que esa emoción es vista por los demás como inapropiada e, incluso, se me reprocha por ella. Creo que en este caso somos responsables de examinar las creencias en que se basa y someterlas a juicio crítico. Es posible que la creencia que suscita la emoción sea inconsciente; en tal caso debemos preguntarnos por ella (el tipo de emoción, que normalmente se vincula con el tipo de creencia que la suscita, es también un buen medio para explicitarla) y hacerla aflorar a la superficie. Una vez explícita ya puedo someterla a juicio y tener ante ella una actitud crítica.

Por supuesto, cabe la posibilidad de que en lugar de cambiar la creencia, me reafirme en ella, y, por tanto, la emoción dudosa sea confirmada (por mí) como racional. Según algunos autores, cabe también que las emociones persistan aun cuando cambie la creencia, que dejen una impresión que pervive más allá de la creencia. La educación emocional tiene sus límites, y no son pocos.

b) Otra vía para evitar o provocar emociones consiste en manipular el contexto en el que surge la emoción. En palabras de W. LyONS: «Para inducir en uno mismo una emoción, podríamos estudiar bajo qué condiciones ocurre la emoción apropiada y más adelante deliberadamente construir o duplicar tal situación» ${ }^{20}$. Igualmente, para mantenerla viva podríamos tratar de promover las circunstancias en las que la emoción surge con mayor facilidad. También podemos tratar de evitar que surja una emoción (o atajarla si ya nos embarga) rehuyendo las situaciones que sabemos que suelen provocarnos tal emoción.

Para poder ejercer este tipo de control sobre las emociones es necesario, en primer lugar, que sepamos y podamos reproducir o evitar las circunstancias del contexto, esto es, que contemos con un repertorio de estrategias de manipulación del contexto;

\footnotetext{
${ }^{20}$ LYONS, 1993, p. 257.
} 
en segundo lugar, es necesario que conozcamos qué tipo de condiciones despiertan las emociones que queremos controlar. Esto, sin embargo, no es fácil: exige tener un catálogo lo suficientemente concreto de cosas que, por ejemplo, me dan miedo, me producen ira, despiertan mi desdén, me causan sorpresa, suscitan mi empatía, mi envidia etc., de manera que pueda reproducir o suprimir las condiciones que hacen que surjan estas emociones.

Esta vía para la educación emocional, como vemos, pasa por conocernos a nosotros mismos. Esto hace difícil que la educación de nuestras emociones venga de fuera. Las emociones genéricas, o clases de emociones, se corresponden con ciertos tipos de creencias, pero éstas han de ser descritas muy genéricamente: el miedo se corresponde con la creencia de que algo es peligroso. Pero qué es lo que juzgamos peligroso, aunque haya un núcleo común, varía de un sujeto a otro.

Un caso especial de esta manera de controlar nuestras emociones sería lo que LYONS llama «técnicas de choque», que podemos usar para tratar de vencer algunas de nuestras emociones. Esta técnica consiste en buscar expresamente las circunstancias en las que aparecen las emociones que deseamos vencer y negarse a ceder a los deseos que generan ${ }^{21}$. Se trata de una de las técnicas usadas para la terapia de algunas fobias (por ejemplo, un método de «curar» la claustrofobia consiste en someter al individuo a encierros en lugares cada vez más pequeños).

c) Ya que las emociones surgen cuando vemos satisfechos o frustrados nuestros deseos, esto es, cuando alcanzamos o perdemos estados de cosas que consideramos valiosos, un medio para reprimirlas consiste en reprimir nuestros deseos o negarnos a tratar de satisfacerlos. Si siento una enorme tristeza y frustración por no poder estar con la persona que amo, lo mejor es que me olvide de ella. Tenemos estrategias para ello: puedo distraerme, orientarme hacia otros objetivos, realizar trabajos que requieran esfuerzo y concentración, etc. Esta negación de deseos no tiene por qué ser general y llevarse a las medidas drásticas de los estoicos. No se trata de prescindir de las emociones, sino de prescindir de aquellas que son irracionales en alguno de los anteriores sentidos. No hace falta negarlo todo, sino sólo los deseos perjudiciales o lesivos para mí o para la sociedad. La educación sentimental puede tratar de inculcar cuáles son los fines aceptados como legítimos por la sociedad y tratar de reprimir los deseos inapropiados. Se trata de un proceso de educación en los valores apropiados, con todas las dificultades que ello conlleva.

\section{EMOCIONES Y ACCIONES: LA «CONDICIÓN DE MOTIVACIÓN»}

Es indudable que las emociones tienen una función de motivación de la conducta. De hecho, es frecuente mencionar una emoción para explicar una acción o una omisión o, incluso, una intención. Podemos decir que Alfredo no vino porque tenía miedo de subir a un avión, que Pedro le gritó a Marta porque está ofendido con ella, que Pilar tiene la intención de ir a ver a Juan porque está desesperada, que Edipo se sacó los ojos porque no soportaba su culpa y su vergüenza, que ROUSSEAU —él mis-

21 LYONS, 1993, p. 263. 
mo lo dice- escribió sus Confesiones para disipar la sensación de culpa por haber acusado a otra persona de una falta que había cometido en su juventud, que Aquiles volvió a la batalla movido por la ira ante la muerte de Patroclo a manos de Héctor. Los filósofos distinguen, a propósito de la conducta, dos tipos de explicaciones: Por un lado, las explicaciones que señalan las razones (deseos, creencias, intenciones, etc.) por las que un sujeto realizó determinada acción; estas explicaciones tratan de dar algún antecedente de la acción que hace que ésta aparezca como racional desde algún punto de vista. La estructura estándar de este tipo de explicaciones consiste en mostrar que la conducta del agente fue racional a la luz de ciertos deseos suyos y ciertas creencias acerca de cómo satisfacerlos. Por otro lado, las explicaciones que señalan las causas mecánicas (esto es, excluyendo de este sentido de causa a las razones) que determinaron la conducta. Las primeras son explicaciones que presuponen la libertad y la racionalidad del agente, tratando de mostrar los factores que influyeron en la formación de la intención con la que actuó; las segundas no las presuponen, y pueden verse precisamente como amenazas a esa libertad. Las emociones proporcionan ambos tipos de explicaciones de la acción (dicho de otra manera, influyen de dos maneras distintas en la acción: participando en la formación de la intención y constriñendo la libertad de actuar).

\subsection{Las emociones y la explicación de la acción basada en razones}

Para entender el papel de las emociones en la génesis de la acción hay que recordar su conexión con los deseos y las creencias. Como hemos visto, muchas emociones surgen cuando se evalúa un evento como relevante para la satisfacción o frustración de un deseo o una preferencia, en último término vinculado con el bienestar del sujeto o de sus allegados. De manera que ciertos deseos forman parte de la red de estados mentales necesarios para que se produzca una emoción, esto es, toman parte en la generación de la emoción. Podemos llamar a estos deseos deseos previos a la emoción. Pero, por otro lado, en ocasiones las emociones se ven asociadas a otros deseos, que no son previos, sino de alguna manera derivados de ellas ${ }^{22}$. Quien ama, porque ama, desea hacer todo lo posible para estar con la persona amada; quien se ve sorprendido, en tanto que sorprendido, desea saber más; quien tiene miedo, porque teme, desea huir; quien tiene vergüenza desea ocultarse; quien siente remordimientos desea reparar el daño; etc. (no obstante, no todas las emociones se asocian de esta forma a deseos). Llamaré a estos deseos deseos derivados de la emoción. La misma distinción puede hacerse respecto de las creencias: una cosa son las creencias que hacen que surja la emoción y otras las creencias que la emoción suscita. Pues bien, la conexión entre las emociones y las acciones se da a través de los deseos y las creencias que las emociones mismas contribuyen a generar. Es el hecho de que las emociones generen deseos y creencias, o participen en los mecanismos de generación de deseos y creencias, lo que hace que sean (indirectamente) razones para la acción.

22 R. WOLLHEIM, cuyas observaciones sobre cómo influyen las emociones en la generación de acciones inspiran en bastante medida lo que sigue, señala que «es difícil imaginar una formación seria de los deseos, si no es en relación con las emociones. Y ahora sugiero lo contrario: que en la actualidad resulta complicado imaginar una emoción de cierta seriedad que no dé pie a un deseo», WOLLHEIM, 2006, p. 225. 
Creo que hay básicamente tres mecanismos por los cuales las emociones intervienen en el entramado de las razones para la acción:

a) En primer lugar, las emociones contribuyen a generar deseos que están instrumentalmente conectados con los deseos previos o preferencias que el sujeto quiere satisfacer. Las emociones negativas (esto es, las que surgen cuando evaluamos un evento como un obstáculo para satisfacer nuestro deseo principal o previo), generan deseos de resolver o mitigar o eliminar el obstáculo que nos impide satisfacer nuestro deseo principal. Las emociones positivas (aquellas en las que evaluamos el evento como facilitador de nuestro objetivo) pueden generar deseos tendentes a aprovechar el efecto beneficioso del evento o a disfrutar del objetivo satisfecho.

Por ejemplo, en la emoción del miedo se pone en riesgo mi deseo previo de conservar mi integridad física o mi estatus, surgiendo el deseo derivado de recuperar una posición de seguridad (obsérvese que, si no tengo miedo, el deseo derivado no surge, aunque ciertamente tenga el deseo previo y la situación sea objetivamente peligrosa). Un ejemplo menos mundano: La angustia de Julieta ante la oposición de su familia a que contraiga matrimonio con Romeo (su deseo previo) le lleva a intentar un recurso desesperado: planea fingir su muerte (deseo derivado), con el fin de poder huir y casarse en secreto con Romeo más adelante.

b) En segundo lugar, las emociones pueden generar deseos cuya finalidad sea tratar de mitigar la agitación o la sensación de dolor causada por la misma, o alargar o asegurar los aspectos positivos. Por supuesto, la mejor manera de calmar la ansiedad que provoca, por ejemplo, el miedo a perder $x$ es realizar alguna acción que tienda a asegurarnos ese objetivo. Pero en ocasiones algunos deseos y las acciones correspondientes logran mitigar la agitación o la sensación de dolor sin tener con el objetivo principal una conexión instrumental. También el drama de Romeo y Julieta proporciona un ejemplo drástico de este tipo de conexión entre emociones y deseos derivados: Cuando Romeo cree que Julieta ha muerto, su dolor es tal que, no pudiéndolo soportar, decide darse muerte, y lo mismo impulsa a matarse a Julieta cuando ve a Romeo muerto a sus pies. El deseo de venganza puede ser también de este tipo: no va dirigido tanto a eliminar o reducir los efectos de un mal infringido por otro como a procurar cierta satisfacción emocional.

Este tipo de deseos no sólo se pueden dirigir a atenuar o eliminar la agitación o el dolor provocado por las emociones negativas; también se pueden dirigir a promover, asegurar, alargar o rememorar el placer generado por una emoción positiva. Un ejemplo de ello es el deseo de contar a otras personas nuestro éxito en una conquista amorosa, aun a riesgo de indiscreción.

En ocasiones, una emoción negativa desencadena el deseo de no volver a «caer» en una situación emocional del mismo tipo, y una emoción positiva puede desencadenar el deseo de volver a experimentar una emoción del mismo tipo. Son supuestos semejantes a los anteriores, pero más radicales, porque no se trata meramente de reducir o ampliar las sensaciones asociadas a las emociones, sino de eliminar o provocar las emociones mismas. El desengaño amoroso que conduce a la decisión de no volver a enamorarse (de evitar las situaciones en las que puede surgir el amor) puede ser un ejemplo de lo primero, al igual que la decisión de acudir a un psicoterapeuta para que 
nos ayude a superar ciertos miedos, o ciertas fobias. El placer que algunos hallan al sentirse «justamente indignados» hasta el punto de incitarles a buscar nuevas ocasiones para volver a indignarse (incluso, quizá, tergiversando ciertos acontecimientos), esto es, lo que llamamos «cargarse de razón», es un ejemplo de lo segundo.

c) En tercer lugar, las emociones generan creencias que, en combinación con ciertos deseos, constituyen razones para la acción. Como señaló ARISTÓTELES, la relación de las emociones con las creencias o evaluaciones - de manera semejante a lo que sucede en el caso de los deseos- es doble: por un lado, las creencias o juicios evaluativos generan emociones; por otro lado, las emociones influyen en nuestra manera de percibir y evaluar el mundo. Y estas maneras de ver el mundo se combinan con deseos para formar razones completas para la acción que nos impulsan a actuar. Determinar qué tipo de creencias generan las emociones es una cuestión vinculada al problema de la relación entre las emociones y la racionalidad. Quienes asumen que las emociones generan creencias o evaluaciones distorsionadas o irracionales, señalan cómo las emociones afectan a las estimaciones de probabilidad y credibilidad acerca de los hechos que están más allá de nuestro control; nos hacen más optimistas respecto de la eficacia de nuestras acciones; inducen «fantasías»; nos hacen minusvalorar o despreciar las consecuencias de nuestras acciones, etc. Pero también se ha puesto de manifiesto lo contrario: las emociones facilitan en ocasiones la toma de decisiones al poner en primer plano los aspectos importantes de determinadas situaciones, coloreándolos o marcándolos, impidiendo que nos perdamos en una miríada de datos percibidos como uniformemente relevantes. Probablemente es esto lo que hay detrás de los autores que defienden que las emociones son un elemento imprescindible en lo que llaman la «percepción moral», esto es, la capacidad de percibir los aspectos relevantes de una situación con trascendencia moral.

\subsection{Las emociones y la explicación causal-mecanicista de la conducta}

Hay una dimensión de las emociones que no puede dejarse de lado; se trata de la idea - que tiene un claro apoyo en la propia introspección - de que las emociones están en tensión con nuestra autonomía, en el sentido de que sustraen, al menos en parte, nuestras decisiones y acciones del control de nuestra voluntad ${ }^{23}$. Todos hemos sentido en ciertas ocasiones una sensación de pérdida de control debida a alguna emoción. Esta intuición encuentra a su vez apoyo en las investigaciones neurofisiológicas: los estudios neurofisiológicos apuntan a la idea de que las emociones «vienen gestionadas» por las zonas más primitivas del cerebro desde un punto de vista evolutivo (el sistema límbico y la amígdala), que son relativamente independientes de las zonas que regulan los procesos superiores del razonamiento y la acción voluntaria (como los lóbulos prefrontales y la corteza cerebral). De esta manera, habría un «cerebro racional» y un «cerebro emocional», sólo parcialmente relacionados entre sí, que plantean al ser humano un conflicto en su «vida psíquica» (tradicionalmente descrito como el conflicto entre pasión y razón) ${ }^{24}$.

\footnotetext{
23 MOYA, 2000.

24 Moya, 2000, p. 72. Véase también Damasio, 2004; ChÓliz MonTaÑÉs, 2005, y Simón, 1997.
} 
¿Por qué las emociones pueden ser una amenaza para nuestra libertad de actuar? En primer lugar, como hemos visto, las emociones «filtran» la percepción de los rasgos de una situación, determinando, en buena medida de forma mecánica, nuestras creencias. De esta manera, afectan causalmente a la formación de nuestras intenciones. Pero, además, al parecer las emociones limitan las respuestas que podemos dar ante una determinada situación. A. DAMASIO ha postulado la hipótesis de los «marcadores somáticos» para explicar este efecto ${ }^{25}$ : de acuerdo con este autor, mientras las estructuras superiores del cerebro (el «cerebro racional») analizan las consecuencias y la situación resultante de distintas alternativas de acción posibles, el «cerebro emocional» señala cada alternativa de acción imaginada con una «etiqueta» que nos indica qué consecuencias emocionales tendría tal alternativa en caso de ser llevada a cabo; esto es, si despertaría una emoción positiva o negativa. En palabras de V. M. SIMÓN: «El resultado de este "marcaje" le permite al cerebro descartar con gran rapidez las posibilidades de actuación que han sido, por así decirlo, "calificadas" con mala nota en este breve examen emocional. Y, por el contrario, en el caso de las posibilidades marcadas positivamente, le abre el camino a preseleccionarlas para darles preferencia como candidatas a la elección final. El procedimiento permite una velocidad de procesamiento con la que los cálculos meramente racionales no pueden competir» ${ }^{26}$. DAMASIO defiende su hipótesis con el fin de mostrar la contribución de las emociones a la toma de decisiones racional (sin la intervención de las emociones, el «cerebro racional» no podría analizar todas las alternativas relevantes para una decisión compleja en un tiempo razonable); sin embargo, es indudable que, si la hipótesis es cierta, dado que no controlamos la actividad de «marcar emocionalmente» las distintas alternativas de acción (puesto que esto depende de factores hereditarios y de nuestras experiencias anteriores), plantea un importante desafío a nuestra capacidad de formarnos libremente nuestras intenciones ${ }^{27}$.

\section{CONCLUYENDO: EMOCIONES Y RESPONSABILIDAD}

1. Hemos visto que las emociones no son meras sensaciones, sino que tales sensaciones van acompañadas (entre otros elementos, como los cambios fisiológicos o la tendencia a cierta conducta) de cierto tipo de creencias: juicios evaluativos acerca de si cierto hecho facilita u obstaculiza un deseo, un objetivo, una preferencia o un plan. Al incluir una creencia entre sus elementos, las emociones entran dentro del reino de la racionalidad, en el doble sentido de que, por un lado, son susceptibles de ser evaluadas como justificadas o no, de acuerdo con diversos estándares, y, por otro lado, de que entran a formar parte de las explicaciones de la acción basadas en razones.

25 Las investigaciones e hipótesis de DAMASIO están descritas de manera introductoria para no especialistas en su libro El error de Descartes. DAMASIO, 2004.

26 SiMÓN, 1997, p. 375.

27 De hecho, Damasio ilustra su hipótesis con el caso de las abejas, que gracias a un mecanismo similar que conecta ciertos estímulos (tamaño, forma y color de las flores) con ciertas respuestas (acercarse o no a la flor) parecen tener la capacidad de hacer un cálculo de probabilidades y tomar la decisión de si se acercan o no a una determinada flor para recolectar su polen (DAMASIO, 2004, p. 220). Obviamente, no hay nada intencional —ni racional— en este mecanismo. 
2. Hemos visto también que las emociones — bajo esta nueva visión — cumplen las tres condiciones de la responsabilidad: Son susceptibles de ser evaluadas como adecuadas o inadecuadas, son parcialmente controlables (indirectamente) y pueden tener consecuencias (en forma de acciones) con impacto y relevancia social y moral. Por ello, creo que se puede responsabilizar moralmente a las personas por las emociones que tienen o dejan de tener. No obstante, esta es una responsabilidad atenuada (el alcance de tal atenuación es algo que debe determinarse caso por caso), en la medida en que el control que ejercemos sobre nuestras emociones es indirecto e inseguro.

3. Si examinamos los criterios del Derecho penal para modular la responsabilidad por nuestras acciones cuando están motivadas por emociones, nos encontramos con indicios que apuntan a que la concepción de las emociones más adecuada para el Derecho penal es la que tiene en cuenta tanto los elementos fenomenológicos como los intencionales de las emociones. $\mathrm{Y}$ esto es precisamente así porque el Derecho usa como criterio de modulación de la responsabilidad no sólo la intensidad de la emoción, sino también si se trata de una emoción en sí misma reprochable o no.

i) Uno de estos indicios lo encontramos a propósito de la circunstancia de arrebato u obcecación. La jurisprudencia ha establecido los siguientes requisitos —entre otros- para que esta circunstancia pueda apreciarse ${ }^{28}: a$ ) Que el estado pasional tenga su origen en un estímulo o causa externa. b) Que se produzca una alteración de la conciencia y la voluntad (el arrebato o la obcecación en sentido psicológico). No toda emoción, por tanto, produce arrebato u obcecación, y que lo haga depende de la intensidad de la misma. c) Que exista proporcionalidad entre el estímulo y la alteración de la conciencia y la voluntad ${ }^{29}$. d) Que exista una relación causal entre los estímulos y la situación anímica anómala. e) Que la respuesta al estímulo no sea repudiable desde el punto de vista socio-cultural, esto es, que la motivación no sea abyecta o despreciable. Este requisito ha hecho que no se considere arrebato u obcecación la respuesta violenta al deseo de romper una relación afectiva o la agresión a un juez por haber dictado un auto de prisión contra el agresor. También es lo que explica el progresivo rechazo de los celos como emoción susceptible de encuadrarse dentro de esta atenuante, de manera que hemos pasado de sentencias que hablaban, en 1884, del «poderoso estímulo de los celos, tan adecuados para producir arrebato u obcecación» ${ }^{30}$, a afirmar, en 1980, que «los celos amorosos, así expresados, sin otros antecedentes, actos de la víctima, intensidad de los mismos, gravedad de ellos, no tienen entidad por sí mismos para integrar la atenuante» ${ }^{31}$.

Como puede apreciarse, algunos de estos requisitos tienen que ver con la intensidad de los aspectos fenomenológicos y causales de la emoción (como la alteración de la conciencia y la voluntad), pero otros tienen que ver con la posibilidad de evaluar la emoción como adecuada o no, razonable o no (el requisito de que la emoción no sea repudiable desde un punto de vista socio-cultural). Es decir, algunos apuntan a la intensidad de las sensaciones, mientras que otros apuntan al contenido intencional de la emoción, esto es, a la creencia o juicio de valor que la suscita. De forma que para que

\footnotetext{
28 Cotillas Moya, 2007.

29 Cotillas Moya, 2007.

30 STS de 20 de febrero de 1884.

31 STS de 25 de febrero de 1980.
} 
la circunstancia de arrebato u obcecación tenga un efecto atenuador de la responsabilidad se exige no sólo que la alteración fisiológica y psicológica sea tal que produzca una disminución de la imputabilidad, sino también que la emoción no merezca por sí misma (al margen de la acción que ha motivado) un reproche: esto es, que no seamos responsables de tener una emoción inadecuada. Las emociones inadecuadas no dan lugar, sea cual sea su intensidad, a una disminución de la responsabilidad penal. El Tribunal Supremo ha afirmado que el fundamento de la disminución de la pena en los casos de arrebato y obcecación está en la reducción del control de nuestras acciones en los casos de emociones intensas (atenuación, por tanto, de la imputabilidad) ${ }^{32}$. Pero si se tiene en cuenta el requisito de la razonabilidad introducido por él mismo, el fundamento del efecto atenuador de esta circunstancia no es meramente la reducción de la imputabilidad del agente, sino también que — a pesar de la acción que realizó- éste tuvo una emoción razonable. Si no fuera así, habría que pensar que también en los casos en los que la emoción es aberrante (el racismo, por ejemplo), si es intensa, habría que reducir la pena.

ii) Otro indicio de la superioridad de la concepción mixta frente a la tradicionalmente asumida por los juristas lo encontramos en ciertas circunstancias agravantes que podrían interpretarse como casos en los que el hecho de tener una emoción inadecuada incrementa la responsabilidad por la acción realizada. Por ejemplo, la prevista en el art. 22 del Código Penal español, según la cual es circunstancia agravante «cometer el delito por motivos racistas, antisemitas u otra clase de discriminación referente a la ideología, religión o creencias de la víctima, la etnia, raza o nación a la que pertenezca, su sexo u orientación sexual, o la enfermedad o minusvalía que padezca». Estas agravantes, o algunas de ellas, tienen un fuerte componente emocional. El racismo, el antisemitismo, la homofobia, el sexismo, etc., pueden verse como odio a las personas basado en ciertos rasgos de las mismas que el sujeto evalúa como obstaculizadores de alguna preferencia suya. Que estas emociones agraven la pena (por muy intensas que sean, esto es, por mucho que puedan hacer perder el control de la conducta), sólo puede explicarse si se asume que el Derecho toma en consideración que tales emociones son inadecuadas (por basarse en juicios de valor incorrectos y estimular acciones lesivas de bienes fundamentales, como la igualdad). El hecho de que tales emociones no son adecuadas (y no algún aspecto relacionado con la dimensión fenomenológica de las emociones) es, en estos casos, el fundamento de la agravación de la responsabilidad.

iii) Por último, sólo desde una concepción que tenga en cuenta el elemento intencional de las emociones puede explicarse el cambio de valoración que éstas experimentan a lo largo del tiempo. Pensemos, por ejemplo, en el ya citado caso de los celos, que han pasado de ser una atenuante típica a ser mirados con recelo como una emoción que expresa juicios de valor inadecuados sobre las mujeres y, por tanto, cercanos incluso a ciertas agravantes. Este cambio de valoración de los celos no puede explicarse atendiendo a su intensidad.

4. Si las anteriores consideraciones son acertadas, puede afirmarse que el «juego» de las atenuantes y agravantes de carácter emocional que tiene en consideración el

32 STS de 29 de septiembre de 1989. 
Derecho penal presupone la aceptación por parte de éste de que somos responsables por las emociones que tenemos, cuando éstas se traducen en conductas lesivas. Dicho de otra manera, el que tengamos emociones inadecuadas — desde el punto de vista de los juicios de valor y las creencias que éstas incorporan- no le es indiferente a nuestro Derecho penal.

\section{BIBLIOGRAFÍA}

Casacuberta, D., 2000: ¿Qué es una emoción?, Barcelona, Crítica.

ChÓliz Montañés, M., 2005: Psicología de la emoción: El proceso emocional, texto completo en www.uv.es/=choliz.

Cotillas Moya, J. C., 2007: «La circunstancia atenuante de arrebato, obcecación u otro estado pasional semejante», en La Ley Penal, núm. 27.

DAmASIO, A. R., 2004: El error de Descartes. La emoción, la razón y el cerebro bumano, Barcelona, Crítica, trad. de J. DOMÉnEC Ros.

Elster, J., 2002: Alquimias de la mente. La racionalidad y las emociones, Barcelona, Paidós, trad. de A. Santos Mosquera.

GonZÁLEZ LAGIER, D., 1997: «Cómo hacer cosas con acciones. En torno a las normas de acción y las normas de fin», en Doxa, núm. 20.

JAmes, W., 1992: «¿Qué es una emoción?», incluido en CALhoun, Ch., y Solomon, R. C. (comps.), ¿Qué es una emoción? Lecturas clásicas de psicología filosófica, México, Fondo de Cultura Económica, trad. de M. CASO.

LyONS, W., 1993: Emoción, Barcelona, Anthropos, trad. de I. JuRADO.

Mosterín, J., 1987: Racionalidad y acción bumana, Madrid, Alianza Editorial.

MoyA, C., 2000: «Emociones y libertad», en Thémata, núm. 25.

- 2006: Filosofía de la mente, Universidad de Valencia.

Nusbaum, M. C., 2006: El ocultamiento de lo bumano. Repugnancia, vergüenza y ley, Buenos Aires, Katz, trad. de G. ZADUNAISKY.

Rodríguez GONZÁLEZ, M., 1999: Una introducción a la filosofía de las emociones, Murcia, Huerga\&Fierro.

SEARLE, J., 1992: Intencionalidad, Madrid, Tecnos, trad. de E. UjALdón BeníteZ.

Simón, V. M., 1997: «La participación emocional en la toma de decisiones», en Psicothema, vol. 9 , núm. 2.

Solomon, R. C., 2007: Ética emocional. Una teoría de los sentimientos, Barcelona, Paidós, trad. de P. HERMIDA.

Wollheim, R., 2006: Sobre las emociones, Madrid, A. Machado Libros, colección La Balsa de la Medusa. 